
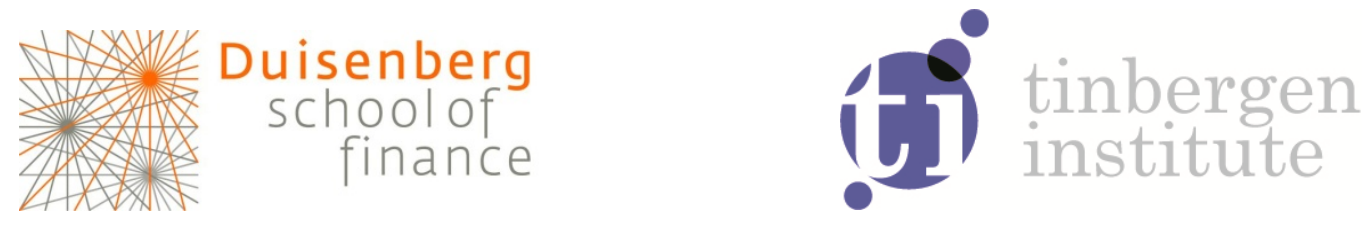

Duisenberg school of finance - Tinbergen Institute Discussion Paper

TI 11-056/ DSF 19

\title{
Voluntary Participation and Intergenerational Risk Sharing in a Funded Pension System
}

Roel M.W.J. Beetsmal,2,3,4

Ward Romp ${ }^{1,2,5}$

Siert J. Vos ${ }^{1,3}$

' Amsterdam School of Economics, University of Amsterdam;

2 Tinbergen Institute;

${ }^{3}$ Netspar;

${ }^{4}$ CEPR, and CESifo;

${ }_{5} \mathrm{Mn}$ Services. 
Tinbergen Institute is the graduate school and research institute in economics of Erasmus University Rotterdam, the University of Amsterdam and VU University Amsterdam.

More TI discussion papers can be downloaded at http://www.tinbergen.nl

Tinbergen Institute has two locations:

Tinbergen Institute Amsterdam

Gustav Mahlerplein 117

1082 MS Amsterdam

The Netherlands

Tel.: +31(0)205251600

Tinbergen Institute Rotterdam

Burg. Oudlaan 50

3062 PA Rotterdam

The Netherlands

Tel.: +31(0)10 4088900

Fax: +31(0)104089031

Duisenberg school of finance is a collaboration of the Dutch financial sector and universities, with the ambition to support innovative research and offer top quality academic education in core areas of finance.

DSF research papers can be downloaded at: http://www.dsf.nl/

Duisenberg school of finance

Gustav Mahlerplein 117

1082 MS Amsterdam

The Netherlands

Tel.: +31(0)20 5258579 


\title{
Voluntary participation and intergenerational risk sharing in a funded pension system*
}

\author{
Roel M. W. J. Beetsma \\ University of Amsterdam, Tinbergen Institute, Netspar, CEPR and CESifo ${ }^{\dagger}$ \\ WARD ROMP \\ University of Amsterdam, Tinbergen Institute and Mn Services ${ }^{\ddagger}$ \\ SiERT J. VOS \\ University of Amsterdam and Netspar ${ }^{\S}$
}

This version: March 16, 2011

\begin{abstract}
We explore the feasibility of a funded pension system with intergenerational risk sharing when participation in the system is voluntary. Typically, the willingness of the young to participate depends on their belief about the future young's willingness to do so. We characterise equilibria with voluntary participation and show that the likelihood of their existence increases with risk aversion and financial market uncertainty. We find that it is likely that mandatory participation is necessary to sustain a funded pension pillar and to let participants benefit from intergenerational risk sharing.
\end{abstract}

${ }^{*}$ We thank, without implicating, for helpful comments Larry Christiano, Wouter den Haan, Lex Meijdam, Gijs Roelofs, Christian Stoltenberg, Ed Westerhout, participants of the Netspar macro theme June 2010 meeting and participants of the Netspar Pension Day November 2010 meeting

${ }^{\dagger}$ Mailing address: Amsterdam School of Economics, University of Amsterdam, Valckenierstraat 65-67, 1018 XE Amsterdam, The Netherlands; Phone: +31.20.5255280; fax: +31.20.5254254; e-mail: R.M.W.J.Beetsma@uva.nl.

${ }^{\ddagger}$ Mailing address: Amsterdam School of Economics, University of Amsterdam, Valckenierstraat 65-67, 1018 XE Amsterdam, The Netherlands; Phone: +31.20.5257344; fax: +31.20.5254254; e-mail: W.E.Romp@uva.nl.

${ }^{\S}$ Mailing address: Amsterdam School of Economics, University of Amsterdam, Valckenierstraat 65-67, 1018 XE Amsterdam, The Netherlands; Phone: +31.20.5257178; fax: +31.20 .5254254 ; e-mail: S.J.Vos@uva.nl. 


\section{Introduction}

All over the world countries introduce funded pension systems in anticipation of the projected rise in aging costs. Often those systems are of the definedcontribution (DC) type, which means that workers save through a pension fund and at retirement receive whatever they have accumulated in their own account. Hence, under such an arrangement much of the potential benefit from intergenerational risk sharing, in particular risk sharing between workers and retirees, will be lost. However, this need not be the case if the funded pension scheme is appropriately designed. For example, in the Netherlands, a country with a large pillar of sectoral and company pension funds, risks are shared among generations of workers and retirees through changes in the contributions paid by workers and through changes in the indexation of pensions and pension rights to wage or price inflation. Participation of employees in the system is mandatory. ${ }^{1}$ This is important, because a risk-sharing arrangement that is not legally enforced is only viable when there exists no ex-post incentive to quit the arrangement whenever a transfer has to be made. In a situation of underfunding (low buffers) of the pension fund, the young would be tempted to leave the system instead of guaranteeing the pensions of the retired through higher contributions. If the buffers are too big, the old will be tempted to close the fund. If participation in a funded pension system is voluntary, the ex-ante benefits of intergenerational risk sharing may be forgone.

In this paper we explore the feasibility and welfare consequences of a funded pension system with voluntary participation and intergenerational risk sharing. So far, there hardly exists any formal analysis addressing this issue. However, we believe that such an analysis is of substantial policy relevance, because the countries that are increasing or planning to increase the funded component of their pension systems, need to take informed decisions about its design. In particular they need to decide whether to introduce certain defined-benefit elements and whether to make participation obligatory. Ongoing discussions and in some instances very slow reform are taking place in the U.S., Austria and Ireland (OECD, 2009). Moreover, as outlined in Holzmann et al. (2008), a number of East-European countries, such as Hungary, Romania and Slovenia, are in the process of transforming parts of their pay-as-you-go (PAYG) state-

\footnotetext{
${ }^{1}$ More precisely, participation is mandatory when there is a collective labour agreement between the social partners (trade unions and firm or employers' organizations). Except for the self-employed this is the case for most of the workers.
} 
provided pensions into private funded systems.

Our analysis takes place in the context of a simple infinite horizon model with two overlapping generations. Voluntary participation is modeled through a participation constraint that requires the expected utility from participation to be at least as large as expected utility under autarky. When financial market performance is bad and, hence, the return on the pension fund portfolio is low, the current young make a transfer to the current retirees. Individuals always have the option to not participate after the current shock has materialised. Participation yields benefits in terms of intergenerational risk sharing. However, numerical results show that the ex-post option to not participate in the system renders a funded system unfeasible for low degrees of risk aversion and when portfolio returns have low variance. In those circumstances the risk-sharing benefits will be lost. Increases in risk aversion and uncertainty about the returns raise the likelihood of a sustainable funded system based on voluntary participation. However, risk sharing would still be less than under the optimal arrangement with obligatory participation. Raising risk-aversion and volatility further, we find that the optimal solutions under voluntary and obligatory participation coincide.

This paper draws from several strands of the literature. First, there is a literature on intergenerational risk sharing in pension systems. Bohn (1999, 2003) analyses such risk sharing in PAYG pension systems. Krueger and Kubler (2006) find that PAYG pension systems can only be welfare improving when markets are incomplete, while, moreover, their welfare effects depend on the degrees of risk aversion and intertemporal substitution. Gottardi and Kubler (2006) extend the analysis of Krueger and Kubler (2006) and Ball and Mankiw (2007) compare risk sharing of an overlapping generations economy under autarky and in the presence of a full set of state-contingent assets. De Menil and Sheshinsky (2003), Hassler and Lindbeck (1997) and Matsen and Thogersen (2004) explore the trade off between a PAYG and a funded pension system. The optimal relative sizes of the two components of the pension system depend on the preferences and the characteristics of the stochastic processes driving wages and returns. Beetsma and Bovenberg (2009) and Beetsma et al. (2011) explore risk sharing through a combination of a PAYG and a fully funded system. Finally, Cui et al. (2009) compare risk sharing in various types of funded pension systems such as an individual DC scheme, a collective DC scheme and a collective DB scheme. 
Second, our paper is linked to the literature on participation constraints. Kocherlakota (1996) and Thomas and Worrall (1988) explore risk-sharing between two types of infinitely-lived agents in which transfers can go both ways between the agents, who always have the possibility to walk away from the risk-sharing agreement. Our setup differs in that our agents only live for two periods and transfers always go from the young to the old. The young are prepared to make such transfers because they expect the future young to also honour the risk-sharing arrangement. Krueger and Perri (2009) explore limited participation constraints when public insurance is introduced into a market in which private insurance contracts are not fully enforcable. They show that public insurance can crowd out private insurance, because agents who break the private contract have the option of joining the public insurance contract.

The third strand of the literature to which this paper is related is that on discontinuity risk in pension systems. In Teulings and De Vries (2006) the young may be exposed to equity risk already before they enter the labour market, implying that they may have accumulated losses even before they start working. Under those circumstances young individuals may prefer not to participate in the pension fund. Bovenberg et al. (2007) also discuss the problem of negative buffers that make it unattractive for new young generations to enter a pension fund. Other articles exploring discontinuity risk in funded pension systems are Van Ewijk et al. (2008), Gollier (2008) and, in particular, Westerhout (2009), which is closest to our analysis. He employs an infinite horizon model with two overlapping generations. He quantifies the feasible amount of risk-sharing under the assumption that the old are bound by their pension contract and the young are free to choose whether they will join the fund. They will not join when the financial position of the fund is weak. Hence, risk sharing is possible only for a limited set of states. An important assumption is that the return on the pension funds' assets exceeds that on private savings. This makes it relatively attractive to join a pension fund. We do not need to make such an assumption.

The remainder of this paper is structured as follows. In Section 2 we set up the model and solve for the autarky solution. Section 3 introduces a pension fund and solves for the optimal transfer rule in the absence of a participation constraint. In Section 4, we introduce the participation constraint and characterise the various equilibria. This section also solves for the optimal pension fund rule. Section 5 works out a numerical example. Finally, Section 6 con- 
cludes the main text of the paper.

\section{Model and autarky solution}

We set up an infinite-horizon overlapping generations model. In each period, a new, young generation is born. The generation born in period $t$ will be referred to as the "period- $t$ generation". Each generation consists of identical individuals and lives for two periods. In the first period of its life, the generation works, consumes and saves for its old age. When old in the second period of its life, the generation is retired and consumes all of its savings. Savings can be invested in a single risky asset. We assume that subsequent returns are independently distributed. All generations are of the same size, which we normalise to unity.

The preferences of an individual born in period $t$ are given by:

$$
U_{t}=u\left(c_{t, t}\right)+\beta E_{t}\left[u\left(c_{t+1, t}\right)\right],
$$

where $c_{t, t}$ denotes consumption in the first period of its life and $c_{t+1, t}$ denotes consumption in the second period of its life. Hence, the first subscript denotes the period in which consumption takes place and the second subscript denotes the period in which the individual is born.

In the absence of any form of pension system, that is, under "autarky" (denoted by superscript "a"), consumption of the period- $t$ generation in the two periods of its life is:

$$
\begin{aligned}
c_{t, t} & =w_{t}-s_{t}, \\
c_{t+1, t} & =\left(1+r_{t+1}\right) s_{t} .
\end{aligned}
$$

where $w_{t}$ is the exogenous wage rate, $s_{t}$ are private savings under autarky and $r_{t+1}$ is the return on savings. The individual solves the intertemporal consumption allocation problem:

$$
\max _{s_{t}} u\left(w_{t}-s_{t}\right)+\beta E\left\{u\left[\left(1+r_{t+1}\right) s_{t}\right]\right\},
$$

which implies the first-order condition:

$$
u^{\prime}\left(c_{t, t}^{a}\right)=\beta E\left[\left(1+r_{t+1}\right) u^{\prime}\left(c_{t+1, t}^{a}\right)\right] .
$$

Utility under autarky is given by:

$$
U_{t}^{a} \equiv u\left(c_{t, t}^{a}\right)+\beta E_{t}\left[u\left(c_{t+1, t}^{a}\right)\right],
$$

where $c_{t, t}^{a}$ and $c_{t+1, t}^{a}$ are the optimal consumption levels under autarky. 


\section{Introduction of a pension fund}

We introduce a pension system with a simple funding rule. A young person privately saves an amount $s_{t}$ and contributes an amount $\theta$ to the pension fund. The fund invests this contribution in financial assets and pays out the gross return as a pension benefit one period later. In addition, if the fund is underfunded in period $t$, each individual of the period- $t$ generation pays an additional re-funding contribution $\tau_{t}$, which is used to supplement the benefit to the current old generation. The transfer $\tau_{t}$ is non-negative.

\subsection{Individuals}

The consumption levels of a period- $t$ generation member are:

$$
\begin{aligned}
c_{t, t} & =w_{t}-s_{t}-\theta-\tau_{t}, \\
c_{t+1, t} & =\left(1+r_{t+1}\right)\left(s_{t}+\theta\right)+\tau_{t+1} .
\end{aligned}
$$

The individual takes as given the known policy function set by the pension fund and now maximises (1) subject to (7) and (8). This implies the following first-order condition for his intertemporal consumption trade-off:

$$
u^{\prime}\left(c_{t, t}^{p}\right)=\beta E_{t}\left[\left(1+r_{t+1}\right) u^{\prime}\left(c_{t+1, t}^{p}\right)\right],
$$

where $c_{t, t}^{p}$ and $c_{t+1, t}^{p}$ are the optimal consumption levels under participation in period $t$.

\subsection{The pension fund}

We assume that the pension fund applies the very simple funding rule given by:

$$
\tau_{t}=\left\{\begin{array}{c}
\left(r^{*}-r_{t}\right) \theta, \quad \forall r_{t}<r^{*}, \\
0, \quad \forall r_{t} \geq r^{*} .
\end{array}\right.
$$

We choose this rule, because it would be appealing from a practical point of view, as it is intuitive and it would be easy to implement. It features two parameters to be set by the pension fund, $r^{*}$ and $\theta$. In the remainder of the paper, we assume that $\theta$ is given and that the pension fund uses $r^{*}$ as its policy instrument. Figure 1 depicts the size of the transfer as a function of the current asset return and the effect that this rule has on consumption of young and old (the blue solid line). The transfer is rising in the short-fall of the actual market return from $r^{*}$. This dampens the sensitivity of the old's 
Figure 1: Transfer and consumption of young and old

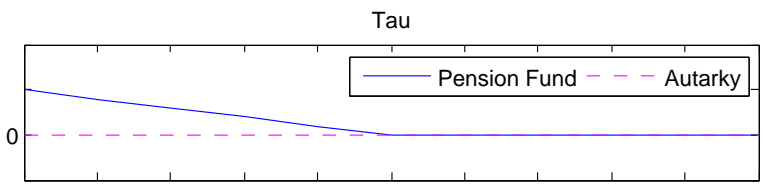

Consumption of the young
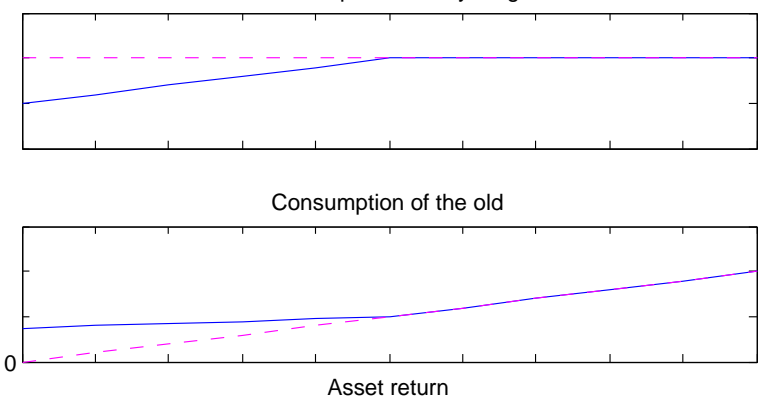

consumption to fluctuations in financial market returns when compared to the autarky situation (the purple dashed line).

The objective of the pension fund is to maximise welfare of the current and all future generations from an ex ante point of view:

$$
\begin{aligned}
\max _{r^{*}} V & =E_{0}\left\{u\left(c_{1,0}\right)+\left[u\left(c_{1,1}\right)+\beta u\left(c_{2,1}\right)\right]+\beta\left[u\left(c_{2,2}\right)+\beta u\left(c_{3,2}\right)\right]+\ldots\right\} \\
& =E_{0} u\left(c_{1,0}\right)+\sum_{t=1}^{\infty} \beta^{t-1} E_{0}\left[u\left(c_{t, t}\right)+\beta u\left(c_{t+1, t}\right)\right] \\
& =E_{0} u\left(c_{1,0}\right)+\sum_{t=1}^{\infty} \beta^{t-1} E_{0}\left[U_{t}^{p}\right]
\end{aligned}
$$

where $E_{0}$ denotes the expectation taken at the start of period 1 , before $r_{1}$ had materialised, and $U_{t}^{p} \equiv u\left(c_{t, t}\right)+\beta u\left(c_{t+1, t}\right)$. Notice that the transfer is not a function of the savings of the previous young generation, but of the time-invariant pension fund rule parameters $r^{*}$ and $\theta$. This implies that all young generations are affected in an identical way by the funding rule and in expectation the decisions of all young generations will be identical. Hence, $E_{0} U_{1}^{p}=E_{0} U_{2}^{p}=\cdots=E_{0} U^{p}$. Using this, we can rewrite (11) as:

$$
\max _{r^{*}} V=E_{0} u\left(c_{1,0}\right)+\frac{1}{1-\beta} E_{0} U^{p}
$$

The optimum is reached by setting $r^{*}$ such that the derivative of the objective function with respect to $r^{*}$ equals 0 :

$$
\frac{\partial V}{\partial r^{*}}=E_{0} \frac{\partial u\left(c_{1,0}\right)}{\partial r^{*}}+\frac{1}{1-\beta} E_{0} \frac{\partial U^{p}}{\partial r^{*}}=0
$$

We call the value for $r^{*}$ implied by this first-order condition $r^{o p t}$. 


\section{The participation constraint}

For any period $t$, we denote the set of possible realisations of the state of the world by $R \equiv[-1, \infty)$. The particular state that actually materialises in period $t$ is exhaustively described by the asset return $r_{t}$ in that period.

We define participation or lack of participation in the pension fund as:

Definition 1: A young generation in period $t$ is said to participate in the pension fund if it chooses to follow the funding rule $\tau=\tau\left(r_{t}\right)$ for the current realization $r_{t}$. It does not participate if it does not follow this funding rule.

Before we continue the analysis we make the following assumptions for an arbitrary period $t \geq 1$ :

Assumption 1: Suppose that all preceding young generations as of period 1 have participated in the pension fund. Each period- $t$ young individual is free to choose whether or not to participate in the pension system after the state $r_{t}$ has materialised.

Assumption 2: Suppose that all preceding young generations as of period 1 have participated in the pension fund. Then, if the period- $t$ young decide not to participate, the economy shifts to autarky and remains in autarky forever after. Hence, none of the future young generations will ever participate.

The ensuing analysis assumes that all preceding young generations as of period 1 have participated in the pension fund. Using the above assumptions we can write the participation constraint for the period- $t$ young individual as:

$$
u\left(c_{t, t}^{p} \mid r_{t}\right)+\beta\left\{E_{t}\left[u\left(c_{t+1, t}^{\text {in }} \mid r_{t}\right)\right]+E_{t}\left[u\left(c_{t+1, t}^{\text {out }} \mid r_{t}\right)\right]\right\} \geq U^{a}, \quad \forall r_{t} \in R,
$$

where $c_{t+1, t}^{\text {in }}\left(c_{t+1, t}^{\text {out }}\right)$ is period $t+1$ consumption of the period- $t$ young when next period's young choose to participate (not participate) in the pension fund.

\subsection{Recursive formulation of the participation constraint}

Since subsequent generations are identical, and assuming that the economy has not shifted to autarky in the past, the participation constraint for each state of the world is identical in any period. This means that we can drop the time 
subscripts and write (12) in terms of current and next-period variables (which are denoted by a prime) as:

$$
u\left(c^{p} \mid r\right)+\beta\left\{E\left[u\left(c^{\text {in }} \mid r\right)\right]+E\left[u\left(c^{\text {out }} \mid r\right)\right]\right\} \geq U^{a}, \quad \forall r \in R,
$$

where a prime denotes next-period variables.

Hence, in our OLG setting, there is a participation constraint analogous to that in the literature that deals with participation constraints in settings with two types of infinitely-lived agents, such as Kocherlakota (1996) and Thomas and Worrall (1988). However, because in our setting the old have no incentive to walk away from the contract, the pension fund does not need to ensure that it delivers at least the utility promised in the previous period. Instead, the fund should ensure that it does not violate the promised funding rule, so that the insurance it promises the current young for the next period remains credible. In addition, in contrast to models with infinitely-lived agents in which transfers can go both ways, in our model transfers always go from young to old individuals. While they may have to make a transfer to the current old, the current young depend on the next period's young for their own insurance. That implies that we do not have a repeated game between agents who can punish each other when one of them deviates from the rule. Hence, the beliefs about the willingness of the next period's young to make a transfer are crucial for the current young's willingness to pay a transfer, as will become clear below.

The next period's young will decide not to participate if the transfer they have to pay is "too large", i.e. if $r^{\prime}<\tilde{r}^{\prime}$, where $\tilde{r}^{\prime}$ denotes the threshold value for the next-period return $r^{\prime}$ that makes next period's young indifferent between participating and not participating. Using this we can write participation constraint (13) as:

$$
\begin{aligned}
U^{a} \leq & U^{p}\left(r \mid \tilde{r}^{\prime}\right) \equiv u\left(w-s^{p}(r)-\theta-\tau(r)\right) \\
& +\beta\left\{\begin{array}{c}
\int_{-1}^{\tilde{r}^{\prime}} p\left(r^{\prime}\right) u\left[\left(1+r^{\prime}\right)\left(s^{p}(r)+\theta\right)\right] d r^{\prime}+ \\
\int_{\tilde{r}^{\prime}}^{r^{*}} p\left(r^{\prime}\right) u\left[\left(1+r^{\prime}\right) s^{p}(r)+\left(1+r^{*}\right) \theta\right] d r^{\prime}+ \\
\int_{r^{*}}^{\infty} p\left(r^{\prime}\right) u\left[\left(1+r^{\prime}\right)\left(s^{p}(r)+\theta\right)\right] d r^{\prime}
\end{array}\right\},
\end{aligned}
$$

where the right-hand side is the utility to the young when the current return is $r$ and the next period's cut-off return for participating is $\tilde{r}^{\prime}$.

\subsection{Equilibrium definition}

We explore equilibria that are defined as follows: 
Definition 2: A recursive equilibrium with participation is an autarky savings decision $s^{a}$, an autarky value $U^{a}$, a pension funding rule $\{\tau(r)\}$, a set of savings decisions under participation $\left\{s^{p}(r)\right\}$, values under participation $\left\{U^{p}\left(r \mid \tilde{r}^{\prime}\right)\right\}$, a current cut-off return $\tilde{r}$ and expectations about the next period's cut-off return $\tilde{r}^{\prime}$, such that

(i) For any $r$, given the funding rule and expectations about future participation, the savings decisions $\left\{s^{p}(r)\right\}$ solve the young generation's optimization problem.

(ii) For $r<\tilde{r}, U^{p}\left(r \mid \tilde{r}^{\prime}\right)<U^{a}$, while for $r \geq \tilde{r}, U^{p}\left(r \mid \tilde{r}^{\prime}\right) \geq U^{a}$.

(iii) The cut-off return for the current young, $\tilde{r}$, computed given the expectation about the future cut-off return $\tilde{r}^{\prime}$, equals the cut-off return for the next period's young, $\tilde{r}^{\prime}$.

(iv) For at least one element $r \in R$, the funding rule sets $\tau(r)>0$ and has $U^{p}\left(r \mid \tilde{r}^{\prime}\right) \geq U^{a}$.

\subsection{Solutions for $\tilde{r}$}

The cut-off return $\tilde{r}$ depends on the size of the current transfer prescribed by the funding rule and the belief about the cut-off return of the young in the next period. If $r \geq r^{*}$, the current young would for sure want to participate. However, if $r<r^{*}$, there may be a cut-off return at which the young are indifferent between participating and not participating in the pension fund. This cut-off return depends on the size of the transfer and on the beliefs about the cut-off return of the next period's young. Because subsequent young generations are identical in all respects under the assumption that all preceding young generations have participated in the pension fund, the cut-off return must be the same for every young generation that still has the option to participate. This implies that $\tilde{r}=\tilde{r}^{\prime}=\left(\tilde{r}^{\prime}\right)^{\prime}=\ldots$. 


\subsubsection{Interior solutions}

An interior solution for $\tilde{r}$ is implicitly defined by:

$$
\begin{aligned}
U^{a} & =U^{p}\left(\tilde{r} \mid \tilde{r}^{\prime}=\tilde{r}\right) \\
& =u\left(w-s^{p}(\tilde{r})-\theta-\left(r^{*}-\tilde{r}\right) \theta\right) \\
& +\beta\left\{\begin{array}{c}
\int_{-1}^{\tilde{r}} p(r) u\left[(1+r)\left(s^{p}(\tilde{r})+\theta\right)\right] d r+ \\
\int_{\tilde{r}}^{r^{*}} p(r) u\left[(1+r) s^{p}(\tilde{r})+\left(1+r^{*}\right) \theta\right] d r+ \\
\int_{r^{*}}^{\infty} p(r) u\left[(1+r)\left(s^{p}(\tilde{r})+\theta\right)\right] d r
\end{array}\right\},
\end{aligned}
$$

Hence, $U^{p}\left(\tilde{r} \mid \tilde{r}^{\prime}=\tilde{r}\right)$ is the utility from participation under the assumption that the portfolio return is at the cut-off return of the current young, $r=\tilde{r}$, and the cut-off return of the future young equals the cut-off return of the current young, $\tilde{r}^{\prime}=\tilde{r}$. A change in $\tilde{r}$ will alter both current utility of the current young, because of the change in the transfer they have to pay, and future utility of the current young, because of the change in the insurance provided by the pension fund. As the Appendix shows, the derivative of $U^{p}\left(\tilde{r} \mid \tilde{r}^{\prime}=\tilde{r}\right)$ with respect $\tilde{r}$ is the sum of a positive and a negative term and its sign is generally indeterminate. However, as the Appendix also shows, function $U^{p}\left(\tilde{r} \mid \tilde{r}^{\prime}=\tilde{r}\right)$ has the property that $U^{p}\left(\tilde{r} \mid \tilde{r}^{\prime}=\tilde{r}\right)$ approaches $U^{a}$ from below as $\tilde{r} \uparrow r^{*}$. In the examples below, we will work with a constant relative risk aversion utility specification. Plots of the resulting function $U^{p}\left(\tilde{r} \mid \tilde{r}^{\prime}=\tilde{r}\right)$ show that it is always convex. Henceforth, we restrict ourselves to the case in which $U^{p}\left(\tilde{r} \mid \tilde{r}^{\prime}=\tilde{r}\right)$ is convex. Under this assumption, depending on whether $U^{p}\left(\tilde{r} \mid \tilde{r}^{\prime}=\tilde{r}\right)$ is larger or smaller than $U^{a}(\tilde{r})$ at $\tilde{r}=-1$, there are three possibilities as illustrated by Figure 2, which as a function of $\tilde{r}$ plots the function $\Delta^{p}(\tilde{r}) \equiv U^{p}\left(\tilde{r} \mid \tilde{r}^{\prime}=\tilde{r}\right)-U^{a}$ :

Situation 1 If $\Delta^{p}(\tilde{r})<0$ at $\tilde{r}=-1$, then $U^{p}\left(\tilde{r} \mid \tilde{r}^{\prime}=\tilde{r}\right)<U^{a}$ for all $-1 \leq$ $\tilde{r}<r^{*}$ and, because $U^{p}\left(\tilde{r} \mid \tilde{r}^{\prime}=\tilde{r}\right)=U^{a}$ at $\tilde{r}=r^{*}$ and $U^{p}\left(\tilde{r} \mid \tilde{r}^{\prime}=\tilde{r}\right)$ is strictly convex on $\left[-1, r^{*}\right]$, the only value for $\tilde{r}$ for which $U^{p}\left(\tilde{r} \mid \tilde{r}^{\prime}=\tilde{r}\right)=U^{a}$ is $\tilde{r}=r^{*}$. This is the situation depicted by the lowest curve in Figure 2. In this case, (14) collapses to:

$$
U^{a}=u\left(w-s^{p}-\theta\right)+\beta \int_{-1}^{\infty} p\left(r^{\prime}\right) u\left[\left(1+r^{\prime}\right)\left(s^{p}+\theta\right)\right] d r^{\prime},
$$

which always holds, because there is no risk sharing in the pension fund. Hence, $s^{p}+\theta=s^{a}$. The pension fund operates as an individual DC arrangement which provides exactly the same utility as autarky. 
Figure 2: Net benefit from participation

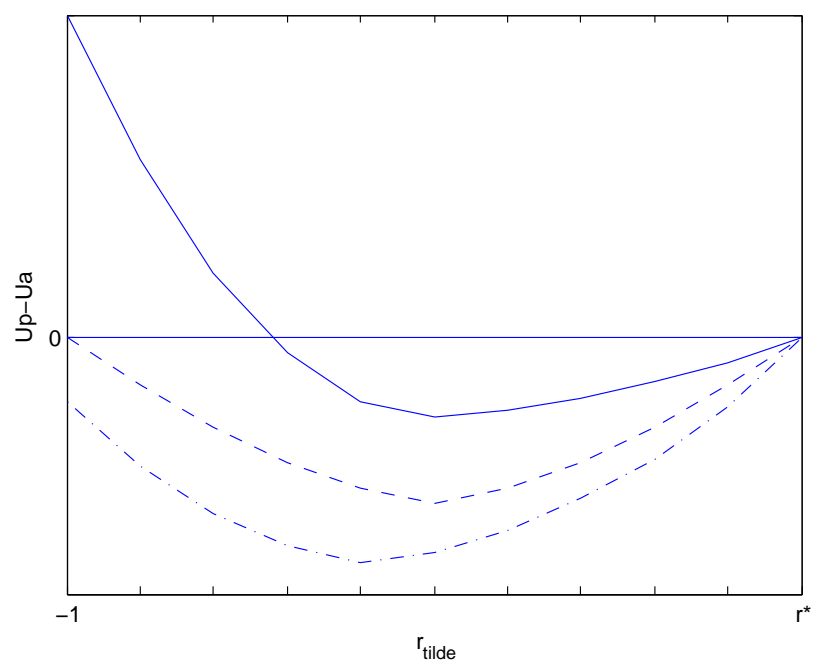

Situation 2 If $\Delta^{p}(\tilde{r})=0$ at $\tilde{r}=-1$, then $U^{p}\left(\tilde{r} \mid \tilde{r}^{\prime}=\tilde{r}\right)<U^{a}$ for all $-1<$ $\tilde{r}<r^{*}$ since $U^{p}\left(\tilde{r} \mid \tilde{r}^{\prime}=\tilde{r}\right)=U^{a}$ at $\tilde{r}=r^{*}$ and $U^{p}\left(\tilde{r} \mid \tilde{r}^{\prime}=\tilde{r}\right)$ is strictly convex on $\left[-1, r^{*}\right]$. In this case, depicted by the middle curve in Figure 2, equation (14) has exactly two solutions for $\tilde{r}$, namely $\tilde{r}=-1$ and $\tilde{r}=r^{*}$. This first solution implies that if the current young believe that the next period's young will join the pension system with certainty, then in the worst scenario today (i.e. $r=-1$ ), the current young are indifferent between participating and not participating. Hence, the pension system continues to exist forever.

Situation 3 If $\Delta^{p}(\tilde{r})>0$ at $\tilde{r}=-1$, as depicted by the upper curve in Figure 2, then $\tilde{r}=-1$ is a corner solution, because under the belief that the next period's young will always participate the current young have higher utility from participating in the pension system than under autarky even if they have to pay the highest possible transfer. Again, $\tilde{r}=r^{*}$ is also a solution. Finally, there exists a third solution $-1<\tilde{r}<r^{*}$, such that $U^{p}\left(\tilde{r} \mid \tilde{r}^{\prime}=\tilde{r}\right)=U^{a}$.

\subsection{Properties of the solutions for $\tilde{r}$}

We shall now further analyse Situation 3. If the current young, given their belief that the next period's young will participate in every state $\left(\tilde{r}^{\prime}=-1\right)$, are also willing to participate, there exist three solutions, namely $\tilde{r}=-1, \tilde{r}=r^{*}$ and a solution $-1<\tilde{r}<r^{*}$. The first two solutions are stable, while the third is a knife-edge solution that will never be realised unless the current young start with an initial belief at exactly that point. Let us denote this solution by $\tilde{r}^{u}$. 
Which one of the two stable equilibria is reached depends on the initial belief of the current young.

\subsubsection{Initial belief between -1 and the unstable solution}

If the current young initially believe that the cut-off return $\tilde{r}^{\prime}$ of the next young generation lies between -1 and $\tilde{r}^{u}$, then we will end up in the equilibrium with $\tilde{r}=-1$. We illustrate this case using Figure 3, in which we plot the solid curve $\Delta^{p}(\tilde{r})$ as a function of $\tilde{r}$ and the dashed curves $U^{p}\left(r \mid \tilde{r}^{\prime}\right)-U^{a}$ for two different values of $\tilde{r}^{\prime}$. Note that there exist an infinite number of such curves, one for each possible belief about next young's cut-off value $\tilde{r}^{\prime}$. Since $U^{a}$ does not depend on $r$, the shape of these curves is identical to that of $U^{p}\left(r \mid \tilde{r}^{\prime}=\tilde{r}\right)$. Hence, they are strictly increasing and concave in $r$ for $r \in\left[-1, r^{*}\right]$. They hit the vertical axis below, at or above the origin.

Take an arbitrary starting value $-1<\tilde{r}_{1}=\tilde{r}_{1}^{\prime}<\tilde{r}^{u}$ for $\tilde{r}=\tilde{r}^{\prime}$. This corresponds to the point where the lower dashed line crosses the solid line. At $r=\tilde{r}_{1}$, one has $U^{p}\left(r \mid \tilde{r}^{\prime}=\tilde{r}_{1}\right)>U^{a}$. Hence, $r=\tilde{r}_{1}$ cannot be the cut-off return $\tilde{r}$ of the current young. While keeping $\tilde{r}^{\prime}$ fixed at $\tilde{r}_{1}$, we decrease $r$, thereby raising the required transfer and reducing expected utility from participation $U^{p}\left(r \mid \tilde{r}^{\prime}=\tilde{r}_{1}\right)$ until we reach the value of $r$ such that $U^{p}\left(r \mid \tilde{r}^{\prime}=\tilde{r}_{1}\right)=U^{a}$. (That is, we move along the lower dashed line to the left until we hit the horizontal axis.) This defines the cut-off return $\tilde{r}_{2}$ of the current young given their initial belief about future participation. However, $\tilde{r}_{2}<\tilde{r}_{1}$, implying that the belief $\tilde{r}^{\prime}=\tilde{r}_{1}$ cannot be an equilibrium belief, as in equilibrium the cut-off returns of all subsequent young generations must be identical. Hence, the current young update their belief about the next young's cut-off return to $\tilde{r}^{\prime}=\tilde{r}_{2}<\tilde{r}_{1}^{\prime}$. However, at $r=\tilde{r}_{2}$, one has $U^{p}\left(r \mid \tilde{r}^{\prime}=\tilde{r}_{2}\right)>U^{a}$. Lowering $r$, we move along the top dashed line to the left until we hit the horizontal axis. This yields the new cut-off return $r=\tilde{r}_{3}$ of the current young defined by $U^{p}\left(r \mid \tilde{r}^{\prime}=\tilde{r}_{2}\right)=U^{a}$. Because $\tilde{r}_{3}<\tilde{r}_{2}, \tilde{r}_{2}$ cannot be an equilibrium cut-off return. We repeat the updating procedure until after a finite number of steps the dashed line either takes us through the origin or we hit the vertical axis at a positive value. The next update then yields the stable equilibrium $\tilde{r}=\tilde{r}^{\prime}=-1$.

In Figure 3 we have depicted a situation in which the stable equilibrium is achieved after three iterations. 
Figure 3: Stable solution with participation

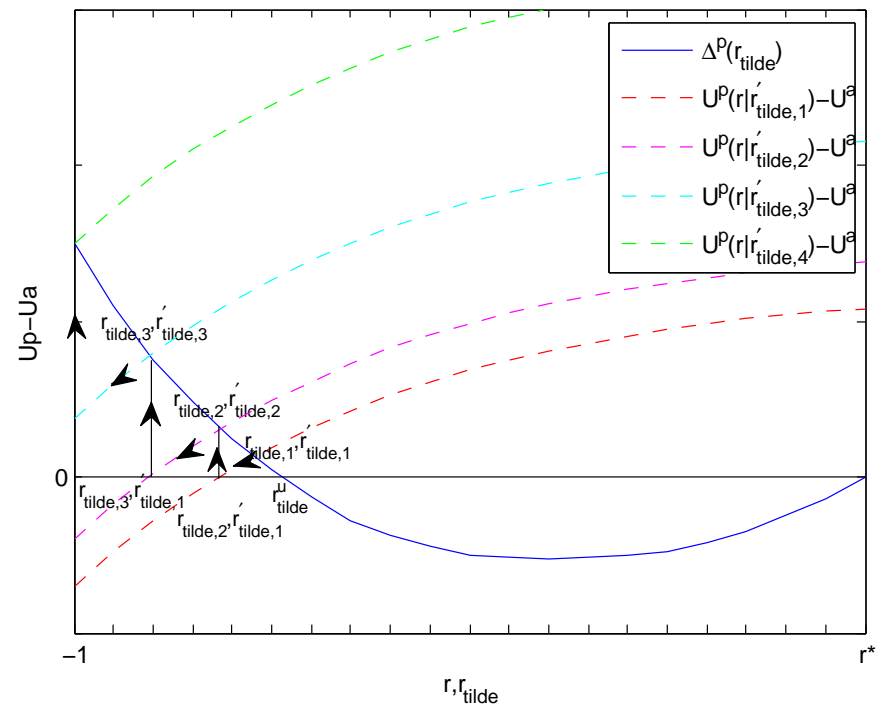

\subsubsection{Initial belief between the unstable solution and $r^{*}$}

We illustrate this case using Figure 4, in which we again plot the solid curve $\Delta^{p}(\tilde{r})$ as a function of $\tilde{r}$ and the dashed curves $U^{p}\left(r \mid \tilde{r}^{\prime}\right)-U^{a}$ for two different values of $\tilde{r}^{\prime}$. There exist an infinite number of these curves, one for each possible value of $\tilde{r}^{\prime}$. All these curves cross $\Delta^{p}(\tilde{r})$ and are strictly positive at $r=r^{*}$.

To see these properties, take an arbitrary starting value $\tilde{r}^{u}<\tilde{r}_{1}=\tilde{r}_{1}^{\prime}<r^{*}$ for $\tilde{r}=\tilde{r}^{\prime}$. We are at the point where the upper dashed line crosses the solid line. That is, at this point, $\Delta^{p}\left(\tilde{r}_{1}\right)=U^{p}\left(r \mid \tilde{r}^{\prime}=\tilde{r}_{1}\right)_{\mid r=\tilde{r}_{1}}-U^{a}$, or equivalently, $U^{p}\left(\tilde{r}_{1} \mid \tilde{r}^{\prime}=\tilde{r}_{1}\right)=U^{p}\left(r \mid \tilde{r}^{\prime}=\tilde{r}_{1}\right)_{\mid r=\tilde{r}_{1}}$. As we move to the right from this point, we compare $U^{p}\left(\tilde{r} \mid \tilde{r}^{\prime}=\tilde{r}\right)$, thus simultanously raising $\tilde{r}^{\prime}$ with $\tilde{r}$ and thereby decreasing the insurance value of pension fund participation, with $U^{p}\left(r \mid \tilde{r}^{\prime}=\tilde{r}_{1}\right)_{\mid r=\tilde{r}}$, in which we keep $\tilde{r}^{\prime}$ constant at $\tilde{r}_{1}$ and thereby keep the insurance value of participation constant. Since $U^{p}\left(\tilde{r} \mid \tilde{r}^{\prime}=\tilde{r}\right)<U^{p}\left(\tilde{r} \mid \tilde{r}^{\prime}=\tilde{r}_{1}\right)$ for $\tilde{r}_{1}<\tilde{r} \leq r^{*}$, the dashed line must lie above the solid line on this interval and, hence, the dashed line is positive at $r^{*}$.

At $r=\tilde{r}_{1}$, we have $U^{p}\left(r \mid \tilde{r}^{\prime}=\tilde{r}_{1}\right)<U^{a}$ so that the current young do not want to participate. Hence, $r=\tilde{r}_{1}$ cannot be the cut-off return $\tilde{r}$ of the current young. While keeping $\tilde{r}^{\prime}$ fixed at $\tilde{r}_{1}$, we raise $r$, thereby reducing the required transfer and raising expected utility from participation $U^{p}\left(r \mid \tilde{r}^{\prime}=\tilde{r}_{1}\right)$ until we reach the value of $r$ such that $U^{p}\left(r \mid \tilde{r}^{\prime}=\tilde{r}_{1}\right)=U^{a}$. (That is, we move along the upper dashed line to the right until we hit the horizontal axis.) This defines the cut-off return $\tilde{r}_{2}$ of the current young given their initial belief about future 
Figure 4: Stable solution without participation

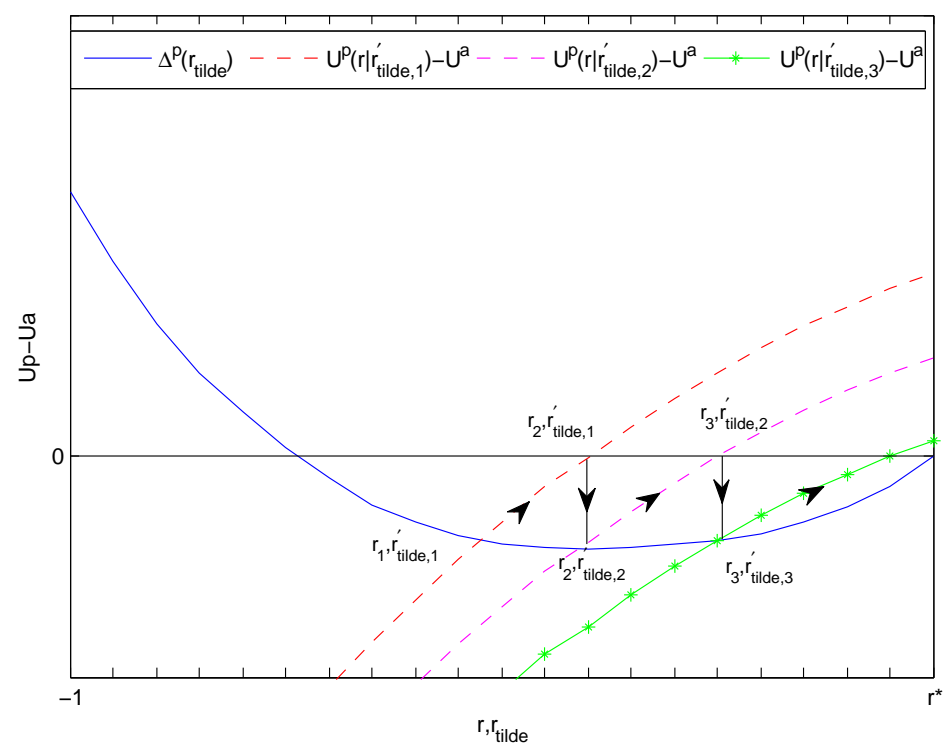

participation. However, $\tilde{r}_{2}>\tilde{r}_{1}$, implying that the belief $\tilde{r}^{\prime}=\tilde{r}_{1}^{\prime}=\tilde{r}_{1}$ cannot be an equilibrium belief, as in equilibrium the cut-off returns of all subsequent young generations must be identical. Hence, the current young update their belief about the next young's cut-off return to $\tilde{r}_{2}^{\prime}=\tilde{r}_{2}>\tilde{r}_{1}$. However, at $r=\tilde{r}_{2}$, one has $U^{p}\left(r \mid \tilde{r}^{\prime}=\tilde{r}_{2}\right)<U^{a}$. Raising $r$, we move along the lower dashed line to the right until we hit the horizontal axis. This yields the new cut-off return $r=\tilde{r}_{3}$ of the current young defined by $U^{p}\left(r \mid \tilde{r}^{\prime}=\tilde{r}_{2}\right)=U^{a}$. Because $\tilde{r}_{3}>\tilde{r}_{2}^{\prime}$, this cannot be an equilibrium cut-off return. We repeat the updating procedure an infinite number of times and converge to the stable equilibrium values $\tilde{r}=\tilde{r}^{\prime}=r^{*}$.

\subsection{Assumption about initial beliefs}

The remainder assumes that each young generation starts with the belief that the next-period young will participate in all states of the world, i.e $\tilde{r}^{\prime}=-1$. If, given this belief, the current young are prepared to participate for $r=-1$, i.e. when the transfer they have to make is at its largest, we have a sustainable pension fund that continues to operate in all periods under any state of the world. If for this initial belief the current young are unwilling to participate for $r=-1$, they will not participate for any return $r \in\left[-1, r^{*}\right]$, and the pension system breaks down. 


\subsection{Feasible pension fund rules}

Until now we have fixed the contract at an arbitrary $r^{*}$ and varied the cut-off value $\tilde{r}$ for young generations. Next, we will vary $r^{*}$ to find the set of feasible funding rules by the pension fund. This part of the analysis closely follows the analysis by Ljungqvist and Sargent (2004, pp.724-726) of Kocherlakota (1996).

We evaluate $U^{p}$ for the worst state of the world $(r=-1)$ under the assumption that the next period's young will participate irrespective of the next period's state of the world (i.e., $\tilde{r}^{\prime}=-1$ ):

$$
\begin{aligned}
U^{p}= & u\left[w-s^{p}-\theta-\left(1+r^{*}\right) \theta\right]+ \\
& \beta\left\{\begin{array}{c}
\int_{-1}^{r^{*}} p\left(r^{\prime}\right) u\left[\left(1+r^{\prime}\right) s^{p}+\left(1+r^{*}\right) \theta\right] d r^{\prime} \\
+\int_{r^{*}}^{\infty} p\left(r^{\prime}\right) u\left[\left(1+r^{\prime}\right)\left(s^{p}+\theta\right)\right] d r^{\prime}
\end{array}\right\} .
\end{aligned}
$$

We can then check for all possible values of $r^{*}$ whether the current young are indeed prepared to participate or not. Start with $r^{*}=-1$. In this case, the young individuals will never make a transfer, so that consumption of the young is constant across all states of the world, and the pension fund operates as an individual DC system. Hence, for $r^{*}=-1$, we have that $U^{p}=U^{a}$. Subsequently, if we increase $r^{*}$ by just a small amount such that $r^{*}>-1$, consumption of the current young decreases slightly in states of the world with $r<r^{*}$, because of the transfer they have to make to the old. If this small increase in $r^{*}$ causes $U^{p}$ to drop below $U^{a}$, then participation is not feasible for any $r^{*}>-1$. This follows from the fact that, as we have seen above, if a pension fund rule is not sustainable for $r=-1$ and $\tilde{r}^{\prime}=-1$, then it is not sustainable at all (as an example, remember the lower curve in Figure 2). However, if the utility loss to the current young from sacrificing consumption in states with $r<r^{*}$ is smaller than the utility gain from better insurance in the next period, then the utility from participating is higher than the utility under autarky and a pension scheme of the type specified here is feasible. As we keep on increasing $r^{*}$, and transfers are becoming larger and cover more states of the world, we reach a point at which the utility loss of sacrificing consumption today exactly equals the utility gain from better insurance value in the next period. This ties down the maximum transfer that can be sustained by our pension arrangement.

We illustrate the argument in Figure 5 where we depict the difference $U^{p}-$ $U^{a}$ for $r=-1$, while varying $r^{*}$ and thus consumption of the young in the worst state of the world. The lower line is the case where even for a tiny increase in $r^{*}$ beyond -1 , utility from participation $U^{p}$ already drops below $U^{a}$. In this 
Figure 5: Feasible pension schemes when varying $r^{*}$

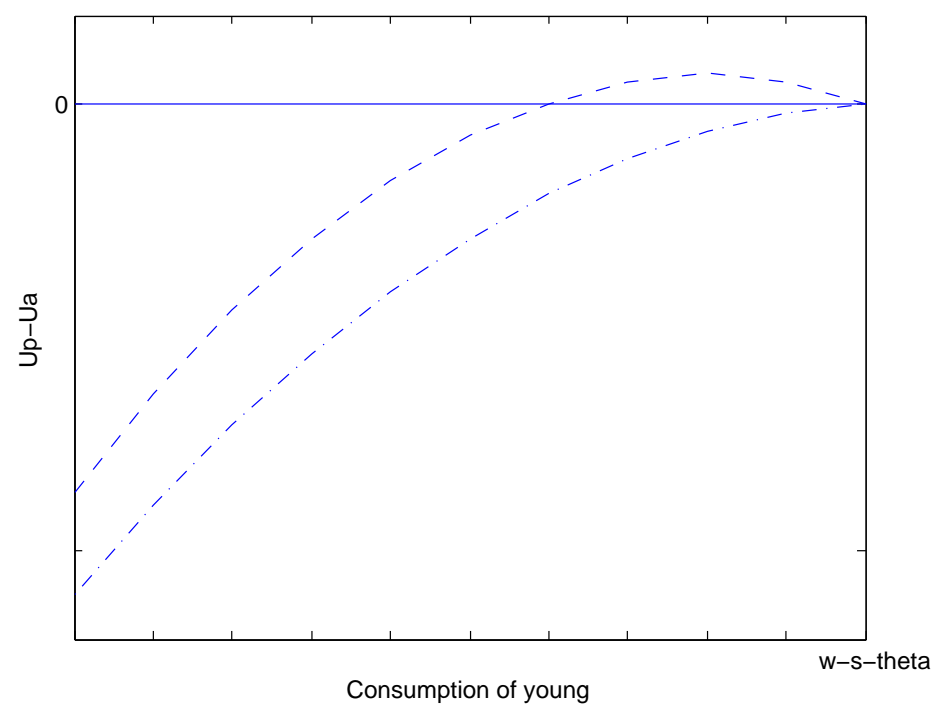

case no pension scheme is feasible. If the structural parameters are such that we have the upper curve instead, then all pension schemes with $r^{*}$ such that $U^{p}-U^{a} \geq 0$ are feasible. From this set of pension schemes we will select the optimal one.

\subsection{The optimal pension fund rule}

We continue to focus on the stable equilibrium with participation in Situation 3 and assume that the funding rule is in place at the start of period 1. Writing out the terms in the pension fund objective function, equation (11), we obtain

$$
\begin{aligned}
E_{0} u\left(c_{1,0}\right) & =\int_{-1}^{r^{*}} p(r) u\left[(1+r) s^{p}+\left(1+r^{*}\right) \theta\right] d r \\
& +\int_{r^{*}}^{\infty} p(r) u\left[(1+r)\left(s^{p}+\theta\right)\right] d r,
\end{aligned}
$$

and

$$
\begin{aligned}
E_{0} U^{p} & =\int_{-1}^{r^{*}} p(r) u\left[w-s^{p}-\theta-\left(r^{*}-r\right) \theta\right] d r \\
& +\int_{r^{*}}^{\infty} p(r) u\left[w-s^{p}-\theta\right] d r \\
& +\beta\left\{\begin{array}{c}
\int_{-1}^{r^{*}} p(r) u\left[(1+r) s^{p}+\left(1+r^{*}\right) \theta\right] d r \\
+\int_{r^{*}}^{\infty} p(r) u\left[(1+r)\left(s^{p}+\theta\right)\right] d r
\end{array}\right\} .
\end{aligned}
$$


We can then write the pension fund objective as:

$$
\begin{aligned}
V\left(r^{*}\right) & =\frac{1}{1-\beta}\left\{\begin{array}{c}
\int_{-1}^{r^{*}} p(r) u\left[w-s^{p}-\theta-\left(r^{*}-r\right) \theta\right] d r \\
+\int_{r^{*}}^{\infty} p(r) u\left[w-s^{p}-\theta\right] d r
\end{array}\right\} \\
& +\frac{1}{1-\beta}\left\{\begin{array}{c}
\int_{-1}^{r^{*}} p(r) u\left[(1+r) s^{p}+\left(1+r^{*}\right) \theta\right] d r \\
+\int_{r^{*}}^{\infty} p(r) u\left[(1+r)\left(s^{p}+\theta\right)\right] d r
\end{array}\right\} .
\end{aligned}
$$

We denote the value for $r^{*}$ that maximises (15) subject to the participation constraint by $r^{p c, o p t}$. Moreover, we define $r^{\max }$ as the value for $r^{*}$ that sets $U^{p}\left(\tilde{r} \mid \tilde{r}^{\prime}=\tilde{r}\right)_{\mid \tilde{r}=-1}=U^{a}$. (If this equation yields no solution $r^{*} \in R$, then we set $r^{\max }=-1$.) Hence, $r^{\max }$ is the maximum value for $r^{*}$, such that current young are always prepared to participate under the belief that the future young always participate.

\section{A numerical example}

This section works out a simple numerical example of the analysis presented in the previous sections. We assume that period utility is given by,

$$
u(c)=\frac{c^{1-\gamma}}{1-\gamma},
$$

with parameter $\gamma$, which captures the constant degree of relative risk-aversion. The baseline values of the model parameters are set as follows. Consistent with standard calibrations in the macro-economics literature, we set $\gamma=5$. Further, we assume that $\beta=0.5$. With one generation spanning 30 years, this corresponds to an annual discount factor of 0.977 . The wage rate is simply a parameter that determines the scale of the economy and we fix it at $w=100$. Given the wage rate $w$, we set $\theta=10$. Hence, this amounts to a pension contribution rate of $10 \%$. We assume that portfolio returns are lognormally distributed and independent over time. In setting the parameters for the portfolio returns, we use the Campbell et al. (2003) figures for equity returns. Specifically, the average annual portfolio return and its standard deviation are set at $\mu=0.089$ and $\sigma=0.182$, respectively which over a period of thirty years translates into an average return of 2.14 and a standard deviation of 0.91 (see Appendix). Given that both risk aversion and the variability of the portfolio return are somewhat on the high side, the conditions for a recursive equilibrium with participation are relatively favourable.

First, we solve for $r^{\text {opt }}$, the optimal choice of the pension fund for $r^{*}$ in the absence of participation constraints. Subsequently, we solve the autarky 
problem, which yields expected utility $U^{a}$. Given $U^{a}$ we can then solve for $r^{\text {max }}$ as well as the constrained optimum $r^{p c, o p t}$ for $r^{*}$. Finally, we compute for the constrained optimum the ex-ante welfare gains $\Omega^{\text {init }}$ for the initial old generation and $\Omega$ for the current young and all future generations. These exante welfare gains are defined as follows:

$$
\begin{aligned}
E_{0} u\left(c_{1,0}^{p}\right) & =E_{0} u\left[\left(1+\Omega^{i n i t}\right) c_{1,0}^{a}\right], \\
E_{0} U^{p} & =u\left[(1+\Omega) c_{t, t}^{a}\right]+\beta E_{0} u\left[(1+\Omega) c_{t+1, t}^{a}\right] .
\end{aligned}
$$

We report the results in Table 1 where we vary the values of the risk aversion parameter $\gamma$, the annual standard deviation of the portfolio return $\sigma$ and the pension contribution $\theta$ around their baseline values. The results show that the higher is the degree of relative risk aversion and the higher is the standard deviation of asset returns, the more likely it becomes that participation in the pension fund is beneficial because of the risk-sharing gains that it provides.

Consider first the case when the pension contribution is at its baseline of $\theta=10$. Then, for a relatively low degree of risk aversion $\gamma=3$ the pension fund is never viable, while for a relatively high degree of risk aversion $\gamma=7.5$ it is viable for any value of $\sigma$ under consideration. For this degree of relative risk aversion, when $\sigma=0.18$ and $\sigma=0.20$, the young are even prepared to make a transfer that is larger than under the optimum without the participation constraint, i.e. $r^{\max }>r^{\text {opt }}$. In this case, the participation constraint is not binding at the unconstrained optimum and, hence, the constrained optimum coincides with the unconstrained optimum, i.e. $r^{p c, o p t}=r^{o p t}$. For $\gamma=5$ the pension fund is viable for high enough $\sigma$, although it does not produce the optimal degree of risk sharing provided under the unconstrained optimum.

In Table 1 we also vary the size of the pension contribution. If $\theta=20$, then for two risk aversion - volatility combinations, $(\gamma=5, \sigma=0.18)$ and $(\gamma=7.5, \sigma=0.15)$, the participation constraint now prohibits any risk sharing, while it did not do so before when $\theta=10$. We also see that in the other case when there is voluntary participation under $\theta=20$, the values for $r^{\max }$ and $r^{p c, o p t}$ have dropped, hence the scope for risk sharing has become smaller. The intuition for this is the following. With a transfer by the current young of the format $\left(r^{*}-r_{t}\right) \theta$, an increase in $\theta$ implies a larger transfer for given $r_{t}<r^{*}$ and, hence, to avoid violation of the participation constraint for given future transfers, $r^{\max }$ needs to fall. However, this reduces the number of states in the future for which the current young will receive a transfer back and the insurance 
Table 1: Results for $100 \%$ equity

\begin{tabular}{|c|c|c|c|c|c|c|c|c|c|c|}
\hline & $\gamma$ & \multicolumn{3}{|c|}{3} & \multicolumn{3}{|c|}{5} & \multicolumn{3}{|c|}{7.5} \\
\hline & $\sigma$ & 0.15 & 0.18 & 0.2 & 0.15 & 0.18 & 0.2 & 0.15 & 0.18 & 0.2 \\
\hline \multirow{5}{*}{$\theta=5$} & $r^{o p t}$ & 0.057 & 0.059 & 0.061 & 0.063 & 0.065 & 0.067 & 0.066 & 0.068 & 0.069 \\
\hline & $r^{\max }$ & -1 & -1 & -1 & -1 & 0.054 & 0.074 & 0.058 & 0.087 & 0.094 \\
\hline & $r^{p c, o p t}$ & -1 & -1 & -1 & -1 & 0.054 & 0.067 & 0.058 & 0.068 & 0.069 \\
\hline & $\Omega^{i n i t}$ & 0 & 0 & 0 & 0 & 0.011 & 0.019 & 0.011 & 0.029 & 0.043 \\
\hline & $\Omega$ & 0 & 0 & 0 & 0 & 0.008 & 0.012 & 0.009 & 0.022 & 0.035 \\
\hline \multirow{5}{*}{$\theta=10$} & $r^{o p t}$ & 0.049 & 0.048 & 0.048 & 0.052 & 0.050 & 0.050 & 0.051 & 0.050 & 0.050 \\
\hline & $r^{\max }$ & -1 & -1 & -1 & -1 & 0.012 & 0.045 & 0.020 & 0.060 & 0.069 \\
\hline & $r^{p c, o p t}$ & -1 & -1 & -1 & -1 & 0.012 & 0.045 & 0.020 & 0.050 & 0.050 \\
\hline & $\Omega^{i n i t}$ & 0 & 0 & 0 & 0 & 0.006 & 0.018 & 0.007 & 0.029 & 0.043 \\
\hline & $\Omega$ & 0 & 0 & 0 & 0 & 0.005 & 0.013 & 0.006 & 0.023 & 0.036 \\
\hline \multirow{5}{*}{$\theta=20$} & $r^{o p t}$ & 0.039 & 0.036 & 0.035 & 0.039 & 0.035 & 0.034 & 0.037 & 0.033 & 0.031 \\
\hline & $r^{\max }$ & -1 & -1 & -1 & -1 & -1 & 0.012 & -1 & 0.033 & 0.043 \\
\hline & $r^{p c, o p t}$ & -1 & -1 & -1 & -1 & -1 & 0.012 & -1 & 0.033 & 0.031 \\
\hline & $\Omega^{\text {init }}$ & 0 & 0 & 0 & 0 & 0 & 0.013 & 0 & 0.028 & 0.042 \\
\hline & $\Omega$ & 0 & 0 & 0 & 0 & 0 & 0.010 & 0 & 0.023 & 0.036 \\
\hline
\end{tabular}

value of the pension falls. For the parameter combinations under consideration the insurance value falls so much that participation by the young is no longer beneficial to them. A reduction in $\theta$ from $\theta=10$ to $\theta=5$ yields the opposite effects and the scope for risk sharing increases.

The degree to which the participation constraint is binding is reflected in the welfare gain associated with participation. If partication is always prevented then, obviously, there can be no welfare gain, while once participation has become beneficial, further increases in risk aversion and the variability of the returns raise the welfare gains from participation. The welfare gain of the initial old is always higher than that of all subsequent generations, because they reap the benefits from the potential transfer, without ever having to pay a transfer themselves.

We also vary the discount factor. A higher discount factor, corresponds to a lower time preference rate, implying that future events become relatively 
Table 2: Results for $100 \%$ equity, $\theta=10$ and varying $\beta$

\begin{tabular}{|l|l|lll|lll|lll|}
\hline & $\gamma$ & & 3 & & \multicolumn{3}{|c|}{5} & \multicolumn{3}{c|}{7.5} \\
\hline & $\sigma$ & 0.15 & 0.18 & 0.2 & 0.15 & 0.18 & 0.2 & 0.15 & 0.18 & 0.2 \\
\hline \multirow{5}{*}{$\beta=0.3$} & $r^{\text {opt }}$ & 0.051 & 0.050 & 0.050 & 0.053 & 0.051 & 0.046 & 0.052 & 0.051 & 0.051 \\
& $r^{\text {max }}$ & -1 & -1 & -1 & -1 & 0.006 & 0.043 & 0.016 & 0.059 & 0.068 \\
& $r^{p c, \text { opt }}$ & -1 & -1 & -1 & -1 & 0.006 & 0.043 & 0.016 & 0.051 & 0.051 \\
& $\Omega^{\text {init }}$ & 0 & 0 & 0 & 0 & 0.005 & 0.012 & 0.007 & 0.029 & 0.043 \\
& $\Omega$ & 0 & 0 & 0 & 0 & 0.004 & 0.017 & 0.006 & 0.022 & 0.035 \\
\hline \multirow{5}{*}{$\beta=0.5$} & $r^{\text {opt }}$ & 0.049 & 0.048 & 0.048 & 0.052 & 0.050 & 0.050 & 0.051 & 0.050 & 0.050 \\
& $r^{\text {max }}$ & -1 & -1 & -1 & -1 & 0.012 & 0.045 & 0.020 & 0.060 & 0.069 \\
& $r^{\text {pc,opt }}$ & -1 & -1 & -1 & -1 & 0.012 & 0.045 & 0.020 & 0.050 & 0.050 \\
& $\Omega^{\text {init }}$ & 0 & 0 & 0 & 0 & 0.006 & 0.018 & 0.007 & 0.029 & 0.043 \\
& $\Omega$ & 0 & 0 & 0 & 0 & 0.005 & 0.013 & 0.006 & 0.023 & 0.036 \\
\hline \multirow{5}{*}{$\beta=0.7$} & $\Omega^{\text {opt }}$ & 0.048 & 0.047 & 0.046 & 0.051 & 0.049 & 0.049 & 0.051 & 0.049 & 0.049 \\
& $r^{\text {max }}$ & -1 & -1 & -1 & -1 & 0.016 & 0.047 & 0.022 & 0.061 & 0.069 \\
& $r^{\text {pc,opt }}$ & -1 & -1 & -1 & -1 & 0.016 & 0.047 & 0.022 & 0.049 & 0.049 \\
& $\Omega^{\text {init }}$ & 0 & 0 & 0 & 0 & 0.007 & 0.019 & 0.008 & 0.029 & 0.043 \\
& $\Omega$ & 0 & 0 & 0 & 0 & 0.006 & 0.013 & 0.007 & 0.024 & 0.037 \\
\hline
\end{tabular}

more important. Hence, participation becomes more attractive to the young. After all, any benefit of participation only materialises in the future. This is borne out by the results in Table 2, in which we vary the discount factor and, for convenience, repeat the middle panel with $\beta=0.5$. Discount factors of $\beta=0.3$ and $\beta=0.7$ correspond annual time preference rates of roughly $4 \%$ and $1 \%$, respectively. A higher discount factor raises $r^{\max }$, the maximum value for $r^{*}$ that supports an equilibrium in which the young are always prepared to participate assuming that the future young do the same. The qualitative effects of an increase in risk aversion or in the standard deviation of the portfolio return that we described earlier are confirmed for different values of the discount factor $\beta$.

So far, the benchmark riskiness of the pension and individual investment portfolios was based on the implicit assumption of a $100 \%$ stake in equity. 
Table 3: Results for 50\% invested in risk free and $50 \%$ in equity

\begin{tabular}{|l|l|lll|lll|lll|}
\hline & $\gamma$ & \multicolumn{3}{|c|}{3} & \multicolumn{3}{c|}{5} & \multicolumn{3}{c|}{7.5} \\
\hline & $\sigma$ & 0.15 & 0.18 & 0.2 & 0.15 & 0.18 & 0.2 & 0.15 & 0.18 & 0.2 \\
\hline \multirow{5}{*}{$\theta=10$} & $r^{\text {opt }}$ & 0.039 & 0.040 & 0.041 & 0.042 & 0.044 & 0.045 & 0.044 & 0.045 & 0.046 \\
& $r^{\text {max }}$ & -1 & -1 & -1 & -1 & -1 & -1 & -1 & 0.046 & 0.057 \\
& $r^{\text {pc,opt }}$ & -1 & -1 & -1 & -1 & -1 & -1 & -1 & 0.045 & 0.046 \\
& $\Omega^{\text {init }}$ & 0 & 0 & 0 & 0 & 0 & 0 & 0 & 0.016 & 0.022 \\
& $\Omega$ & 0 & 0 & 0 & 0 & 0 & 0 & 0 & 0.011 & 0.016 \\
\hline
\end{tabular}

We will now make the implicit assumption that portfolios are half invested in equity and half in a risk-free asset. This implies that both the standard deviation and expected value of the overall portfolio return fall. Following Campbell et al. (2003), we calibrate the risk-free rate at $2.1 \%$ per year (see Appendix). Table 3 reports the numerical outcomes, where $r^{o p t}, r^{\text {max }}$ and $r^{p c, o p t}$ all refer to returns on the total portfolio. For relatively low $(\gamma=3)$ and medium risk aversion $(\gamma=5)$, the participation constraint prevents the existence of the pension fund. For relatively high risk aversion and medium and high variability of equity, there is still scope for pension fund participation, although, not surprisingly, the welfare gains relative to autarky have dropped due to the reduced risk-sharing benefits that the fund provides.

\section{Conclusion}

In this paper we have explored the feasibility and welfare consequences of a funded pension system with voluntary participation and intergenerational risk sharing. Our numerical results showed that the ex-post option to not participate obviates the existence of such a system when both risk aversion and financial market uncertainty are relatively low. Under those circumstances mandatory participation in the system is needed to reap the benefits of intergenerational risk sharing. Increases in these parameters raise the benefits from risk sharing and make the existence of an equilibrium with voluntary participation more likely. For intermediate values of these parameters, risk sharing would still be less than under the optimal arrangement with obligatory participation. How- 
ever, raising risk-aversion and volatility further, the optimal solutions under voluntary and obligatory participation coincide.

Many countries that are currently trying to expand the funded pillar of their pension system need to decide on its design. In particular, will it be a defined-contribution system or will it contain certain defined-benefit elements that allow for intergenerational risk sharing? In the latter case, the question whether participation is obligatory becomes important. Giving individuals too much freedom in deciding whether to participate or not may lead to a breakdown of the system and, hence, to a loss of the risk-sharing benefits. The Dutch funded pillar has long and successfully operated with mandatory participation by employees and employers and the collective sharing of all the risks among all the fund participants. With the current financial crisis and the resulting reduction of the pension buffers, discussions about who will pay for their restoration have put the system under pressure. Because the sustainability of the system is being questioned young generations are increasingly asking themselves whether the same pension provisions will still be there once they have retired. Once large groups start losing their confidence in the system, the pressure to abolish mandatory fund participation will intensify. To prevent a collapse of the system and the loss of the benefits from intergenerational risk sharing, decision makers would be well advised to reconsider the design of the pension arrangement.

\section{References}

[1] Ball, L. and N.G. Mankiw, 2007, Intergenerational risk sharing in the spirit of Arrow, Debreu, and Rawls, with applications to social security design, Journal of Political Economy, Vol. 115, No. 4, 523-547.

[2] Beetsma, R.M.W.J. and A.L. Bovenberg, 2009, Pensions and intergenerational risk sharing in general equilibrium, Economica, Vol. 76, No. 302, 364-386.

[3] Beetsma, R.M.W.J., W.E. Romp and S.J. Vos, 2011, Intergenerational risk sharing, pensions and endogenous labour supply in general equilibrium, mimeo, University of Amsterdam.

[4] Bohn, H., 1999, Social security and demographic uncertainty: the risk sharing properties of alternative policies, NBER Working Paper, No. 7030. 
[5] Bohn, H., 2003, Intergenerational risk sharing and fiscal policy, mimeo, University of California at Santa Barbara.

[6] Bovenberg, L., R. Koijen, T. Nijman and C. Teulings, 2007, Saving and investment over the life cycle and the role of collective pension funds, $D e$ Economist, Vol. 155, No. 4, 347-415.

[7] Campbell, J.Y., Y.L. Chan and L. Viceira, 2003, A multivariate model of strategic asset allocation, Journal of Financial Economics, Vol. 67, No.1, 41-80.

[8] Cui, J., F. de Jong and E. Ponds, 2009, Intergenerational risk sharing within funded pension schemes, mimeo, Tilburg University.

[9] Ewijk, C. van, P. Janssen, N. Kortleve and E. Westerhout, 2009, Naar een reëel kader voor pensioenfondsen, Netspar NEA paper, No.16.

[10] Gollier, C., 2008, Intergenerational risk-sharing and risk-taking of a pension fund, Journal of Public Economics, Vol. 92, 1463-1485.

[11] Gottardi, P. and F. Kubler, 2006, Social security and risk sharing, CESifo Working Paper, No. 1705.

[12] Hassler, J., and A. Lindbeck, 1997, Intergenerational risk sharing, stability and optimality of alternative pension systems, Institute of International Economic Studies Seminar Paper, No. 631

[13] Holzmann, R., L. MacKeller and J. Repansek, 2008, Pension reform in Southeastern Europe, Worldbank Working Paper, No. 46969.

[14] Kocherlakota, N.R., 1996, Implications of efficient risk sharing without commitment, Review of Economic Studies, Vol. 63, 595-609.

[15] Krueger, D. and F. Kubler, 2006, Pareto improving social security reform when financial markets are incomplete!?, American Economic Review, Vol. 96, No. 3, 737-755.

[16] Krueger, D. and F. Perri, 2009, Public versus private risk sharing, NBER Working Paper, No. 15582

[17] Ljunqvist, L. and T. Sargent, 2004, Recursive Macroeconomic Theory, MIT Press, Second edition. 
[18] Matsen, E. and Ø. Thogerson, 2004, Designing social security - a portfolio choice approach, European Economic Review, Vol. 48, 883-904.

[19] Menil, G. de and E. Sheshinski, 2003, The optimal balance of intergenerational transfers and funded pensions in the presence of risk, mimeo, EHESS and Hebrew University.

[20] OECD, 2009, Pensions at a glance 2009: retirement-income systems in OECD countries, www.oecd.org/els/social/pensions/PAG.

[21] Teulings, C. and C. de Vries, 2006, Generational accounting, solidarity and pension losses, De Economist, Vol. 154, No. 1, 63-83.

[22] Thomas, J. and T. Worrall, 1988, Self-enforcing wage contracts, Review of Economic Studies, Vol. 55, 541-554.

[23] Westerhout, E., 2009, Intergenerational risk sharing in time-consistent pension schemes, mimeo, CPB Netherlands Bureau for Economic Policy Analysis.

\section{A Details on first-order condition pension fund with- out participation constraint}

The first-order condition is given by

$$
\frac{\partial V}{\partial r^{*}}=E_{0} \frac{\partial u\left(c_{1,0}\right)}{\partial r^{*}}+\frac{1}{1-\beta} E_{0} \frac{\partial U^{p}}{\partial r^{*}}=0
$$

where, using Leibniz' integral rule,

$$
\begin{aligned}
E_{0} \frac{\partial u\left(c_{1,0}\right)}{\partial r^{*}}= & p\left(r^{*}\right) u\left[\left(1+r^{*}\right)\left(s_{0}^{p}+\theta\right)\right]-p\left(r^{*}\right) u\left[\left(1+r^{*}\right)\left(s_{0}^{p}+\theta\right)\right] \\
& +\int_{-1}^{r^{*}} p(r) u^{\prime}\left[(1+r) s_{0}^{p}+\left(1+r^{*}\right) \theta\right] \theta d r \\
= & \int_{-1}^{r^{*}} p(r) u^{\prime}\left[(1+r) s_{0}^{p}+\left(1+r^{*}\right) \theta\right] \theta d r
\end{aligned}
$$


and

$$
\begin{aligned}
E_{0} \frac{\partial U^{p}}{\partial r^{*}} & =-\int_{-1}^{r^{*}} p(r) u^{\prime}\left[w-s^{p}-\theta-\left(r^{*}-r\right) \theta\right]\left(\frac{\partial s^{p}}{\partial r^{*}}+\theta\right) d r \\
& -\int_{r^{*}}^{\infty} p(r) u^{\prime}\left[w-s^{p}-\theta\right] \frac{\partial s^{p}}{\partial r^{*}} d r \\
& +\beta \int_{-1}^{r^{*}} p(r) u^{\prime}\left[(1+r) s^{p}+\left(1+r^{*}\right) \theta\right]\left[(1+r) \frac{\partial s^{p}}{\partial r^{*}}+\theta\right] d r \\
& +\beta \int_{r^{*}}^{\infty} p(r) u^{\prime}\left[(1+r)\left(s^{p}+\theta\right)\right](1+r) \frac{\partial s^{p}}{\partial r^{*}} d r .
\end{aligned}
$$

\section{B Details on $U^{p}\left(\tilde{r} \mid \tilde{r}^{\prime}=\tilde{r}\right)$}

\section{B.1 $U^{p}\left(\tilde{r} \mid \tilde{r}^{\prime}=\tilde{r}\right)$ approaches $U^{a}$ from below as $\tilde{r} \uparrow r^{*}$}

Recall that $U^{p}\left(\tilde{r} \mid \tilde{r}^{\prime}=\tilde{r}\right)_{\mid \tilde{r}=r^{*}}=U^{a}$. Differentiating $U^{p}\left(\tilde{r} \mid \tilde{r}^{\prime}=\tilde{r}\right)$, as defined in (14), with respect to $\tilde{r}$, and using Leibniz' integral rule, we obtain:

$$
\begin{aligned}
& u^{\prime}\left[w-s^{p}(\tilde{r})-\theta-\left(r^{*}-\tilde{r}\right) \theta\right]\left(\theta-\frac{\partial s^{p}(\tilde{r})}{\partial \tilde{r}}\right) \\
& +\beta p(\tilde{r}) u\left[(1+\tilde{r})\left(s^{p}(\tilde{r})+\theta\right)\right]-0 \\
& +\beta \int_{-1}^{\tilde{r}} p(r) u^{\prime}\left[(1+r)\left(s^{p}(\tilde{r})+\theta\right)\right](1+r) \frac{\partial s^{p}(\tilde{r})}{\partial \tilde{r}} d r \\
& +0-\beta p(\tilde{r}) u\left[(1+\tilde{r}) s^{p}(\tilde{r})+\left(1+r^{*}\right) \theta\right] \\
& +\beta \int_{\tilde{r}}^{r^{*}} p(r) u^{\prime}\left[(1+r) s^{p}(\tilde{r})+\left(1+r^{*}\right) \theta\right](1+r) \frac{\partial s^{p}(\tilde{r})}{\partial \tilde{r}} d r \\
& +\beta \int_{r^{*}}^{\infty} p(r) u^{\prime}\left[(1+r)\left(s^{p}(\tilde{r})+\theta\right)\right](1+r) \frac{\partial s^{p}(\tilde{r})}{\partial \tilde{r}} d r,
\end{aligned}
$$

which we can write as:

$$
\begin{aligned}
& u^{\prime}\left[w-s^{p}(\tilde{r})-\theta-\left(r^{*}-\tilde{r}\right) \theta\right]\left(\theta-\frac{\partial s^{p}(\tilde{r})}{\partial \tilde{r}}\right)+ \\
& \beta\left\{\begin{array}{c}
\int_{-1}^{\tilde{r}} p(r) u^{\prime}\left[(1+r)\left(s^{p}(\tilde{r})+\theta\right)\right](1+r) d r \\
+\int_{\tilde{r}}^{r^{*}} p(r) u^{\prime}\left[(1+r) s^{p}(\tilde{r})+\left(1+r^{*}\right) \theta\right](1+r) d r \\
+\int_{r^{*}}^{\infty} p(r) u^{\prime}\left[(1+r)\left(s^{p}(\tilde{r})+\theta\right)\right](1+r) d r
\end{array}\right\} \frac{\partial s^{p}(\tilde{r})}{\partial \tilde{r}}+ \\
& \beta p(\tilde{r})\left\{u\left[(1+\tilde{r})\left(s^{p}(\tilde{r})+\theta\right)\right]-u\left[(1+\tilde{r}) s^{p}(\tilde{r})+\left(1+r^{*}\right) \theta\right]\right\} .
\end{aligned}
$$

The Euler equation (9) at the current return $r=\tilde{r}$ for $-1 \leq r \leq r^{*}$ is written out as:

$$
\begin{aligned}
& -u^{\prime}\left[w-s^{p}(\tilde{r})-\theta-\left(r^{*}-\tilde{r}\right) \theta\right]+ \\
& \beta\left\{\begin{array}{c}
\int_{-1}^{\tilde{r}} p(r) u^{\prime}\left[(1+r)\left(s^{p}(\tilde{r})+\theta\right)\right](1+r) d r \\
+\int_{\tilde{r}}^{r^{*}} p(r) u^{\prime}\left[(1+r) s^{p}(\tilde{r})+\left(1+r^{*}\right) \theta\right](1+r) d r \\
+\int_{r^{*}}^{\infty} p(r) u^{\prime}\left[(1+r)\left(s^{p}(\tilde{r})+\theta\right)\right](1+r) d r
\end{array}\right\}=0 .
\end{aligned}
$$


Hence, all the terms involving $\frac{\partial s^{p}(\tilde{r})}{\partial \tilde{r}}$ in (16) cancel out and we are left with:

$$
\begin{aligned}
& \frac{\partial U^{p}\left(\tilde{r} \mid \tilde{r}^{\prime}=\tilde{r}\right)}{\partial \tilde{r}}=u^{\prime}\left[w-s^{p}(\tilde{r})-\theta-\left(r^{*}-\tilde{r}\right) \theta\right] \theta+ \\
& \beta p(\tilde{r})\left\{u\left[(1+\tilde{r})\left(s^{p}(\tilde{r})+\theta\right)\right]-u\left[(1+\tilde{r}) s^{p}(\tilde{r})+\left(1+r^{*}\right) \theta\right]\right\} .
\end{aligned}
$$

Evaluated at the point $\tilde{r} \uparrow r^{*}$ this equation becomes:

$$
\left.\frac{\partial U^{p}\left(\tilde{r} \mid \tilde{r}^{\prime}=\tilde{r}\right)}{\partial \tilde{r}}\right|_{\tilde{r} \uparrow r^{*}}=u^{\prime}\left[w-s^{p}\left(r^{*}\right)-\theta\right] \theta>0 .
$$

\section{B.2 Second-order derivative of $U^{p}\left(\tilde{r} \mid \tilde{r}^{\prime}=\tilde{r}\right)$}

Computing the second-order derivative, after simplifying (16) using the Euler equation, yields:

$$
\begin{aligned}
& \frac{\partial^{2} U^{p}\left(\tilde{r} \mid \tilde{r}^{\prime}=\tilde{r}\right)}{\partial^{2} \tilde{r}}=u^{\prime \prime}\left[w-s^{p}(\tilde{r})-\theta-\left(r^{*}-\tilde{r}\right) \theta\right] \theta\left(\theta-\frac{\partial s^{p}(\tilde{r})}{\partial \tilde{r}}\right) \\
+ & \beta p(\tilde{r})\left\{\begin{array}{c}
u^{\prime}\left[(1+\tilde{r})\left(s^{p}(\tilde{r})+\theta\right)\right]\left[s^{p}(\tilde{r})+\theta+(1+\tilde{r}) \frac{\partial s^{p}(\tilde{r})}{\partial \tilde{r}}\right] \\
-u^{\prime}\left[(1+\tilde{r}) s^{p}(\tilde{r})+\left(1+r^{*}\right) \theta\right]\left[s^{p}(\tilde{r})+(1+\tilde{r}) \frac{\partial s^{p}(\tilde{r})}{\partial \tilde{r}}\right]
\end{array}\right\} \\
+ & \beta p^{\prime}(\tilde{r})\left\{u\left[(1+\tilde{r})\left(s^{p}(\tilde{r})+\theta\right)\right]-u\left[(1+\tilde{r}) s^{p}(\tilde{r})+\left(1+r^{*}\right) \theta\right]\right\} .
\end{aligned}
$$

The first line is of ambiguous sign, since $u^{\prime \prime}($.$) is negative and \theta$ and $\partial s^{p}(\tilde{r}) / \partial \tilde{r}$ are both positive (see below). The second line is positive or zero since $p(\tilde{r}) \geq$ 0 and since $u^{\prime}\left[(1+\tilde{r})\left(s^{p}(\tilde{r})+\theta\right)\right]>u^{\prime}\left[(1+\tilde{r}) s^{p}(\tilde{r})+\left(1+r^{*}\right) \theta\right]$, while the sign of the third line is ambiguous, since we do not know the sign of $p^{\prime}(\tilde{r})$. This means that we can not make any general statements about the shape of $U^{p}\left(\tilde{r} \mid \tilde{r}^{\prime}=\tilde{r}\right)$.

\section{B.2.1 The sign of $\partial s^{p}(\tilde{r}) / \partial \tilde{r}>0$}

Denote the left-hand side of (17) by $E U$. The Euler equation can then be compactly written as $E U\left(\tilde{r}, s^{p}(\tilde{r})\right)=0$. Differentiating this expression with respect to $\tilde{r}$ and rewriting the result, yields:

$$
\frac{\partial s^{p}(\tilde{r})}{\partial \tilde{r}}=-\frac{\partial E U / \partial \tilde{r}}{\partial E U / \partial s^{p}}
$$


Working out, we have:

$$
\begin{aligned}
\frac{\partial E U}{\partial \tilde{r}}= & -u^{\prime \prime}\left[w-s^{p}(\tilde{r})-\theta-\left(r^{*}-\tilde{r}\right) \theta\right] \theta \\
& +\beta p(\tilde{r}) u^{\prime}\left[(1+\tilde{r})\left(s^{p}(\tilde{r})+\theta\right)\right](1+\tilde{r})-0 \\
& +\beta \int_{-1}^{\tilde{r}} p(r) u^{\prime}\left[(1+r)\left(s^{p}(\tilde{r})+\theta\right)\right](1+r) 0 d r \\
& +0-p(\tilde{r}) u^{\prime}\left[(1+\tilde{r}) s^{p}(\tilde{r})+\left(1+r^{*}\right) \theta\right](1+\tilde{r}) \\
& +\beta \int_{\tilde{r}}^{r *} p(r) u^{\prime}\left[(1+r) s^{p}(\tilde{r})+\left(1+r^{*}\right) \theta\right](1+r) 0 d r \\
& +\beta \int_{r^{*}}^{\infty} p(r) u^{\prime}\left[(1+r)\left(s^{p}(\tilde{r})+\theta\right)\right](1+r) 0 d r,
\end{aligned}
$$

which we can simplify to:

$$
\begin{aligned}
& \frac{\partial E U}{\partial \tilde{r}}=-u^{\prime \prime}\left[w-s^{p}(\tilde{r})-\theta-\left(r^{*}-\tilde{r}\right) \theta\right] \theta+ \\
& \beta p(\tilde{r})(1+\tilde{r})\left\{u^{\prime}\left[(1+\tilde{r})\left(s^{p}(\tilde{r})+\theta\right)\right]-u^{\prime}\left[(1+\tilde{r}) s^{p}(\tilde{r})+\left(1+r^{*}\right) \theta\right]\right\}>0 .
\end{aligned}
$$

The first line of this derivative is positive, since $u^{\prime \prime}($.$) is negative, while the$ second line is greater than or equal to zero, because $r^{*} \geq \tilde{r}$. Further,

$$
\begin{aligned}
& \frac{\partial E U}{\partial s^{p}}=u^{\prime \prime}\left[w-s^{p}(\tilde{r})-\theta-\left(r^{*}-\tilde{r}\right) \theta\right]+ \\
& \beta\left\{\begin{array}{c}
\int_{-1}^{\tilde{r}} p(r) u^{\prime \prime}\left[(1+r)\left(s^{p}(\tilde{r})+\theta\right)\right](1+r)^{2} d r \\
+\int_{\tilde{r}}^{r^{*}} p(r) u^{\prime \prime}\left[(1+r) s^{p}(\tilde{r})+\left(1+r^{*}\right) \theta\right](1+r)^{2} d r \\
+\int_{r^{*}}^{\infty} p(r) u^{\prime \prime}\left[(1+r)\left(s^{p}(\tilde{r})+\theta\right)\right](1+r)^{2} d r
\end{array}\right\}<0 .
\end{aligned}
$$

Both lines of this derivative are negative, since $u^{\prime \prime}($.$) is negative. Hence, by$ (19), we have $\partial s^{p}(\tilde{r}) / \partial \tilde{r}>0$.

\section{Calibration of the returns process}

The portfolio returns follow a lognormal process and are independently and identically distributed over time. A period in our model corresponds to one generation, which we take here to span 30 years. We use the Campbell et al. (2003) estimates of annual returns on stocks and bonds to construct corresponding 30-year figures. Their sample period covers annual returns over the period 1890 - 1998. We assume the return on T-bills to correspond to that on a risk-free investment. The average annual real return on T-bills is $2.101 \%$. Hence, this is the calibrated value for the risk-free rate of return in our model. Campbell et al. (2003) calculate an average annual equity risk premium of $6.797 \%$. Hence, the 
average annual real equity return is $2.101 \%+6.797 \%=8.898 \%$. Further, it has a standard deviation of $18.192 \%$. Hence, the variance $\sigma_{e, 30}^{2}$ of lognormally distributed thirty-year equity returns is calculated as $\sigma_{e, 30}^{2}=30 \ln \left(1+\frac{\operatorname{var}(r)}{[E(r)]^{2}}\right)=$ $30 \ln \left(1+\frac{0.18192^{2}}{1.08898^{2}}\right)=0.027525 * 30=0.8258$. The corresponding standard deviation is $\sqrt{0.825756}=0.908711$. Next, the mean return over a period of thirty years is calculated as $\ln \left\{[E(r)]^{30}\right\}-\frac{1}{2} \sigma_{e, 30}^{2}=\ln (12.9002)-\frac{1}{2} * 0.8258=2.1443$. To conclude, we calibrate the logarithm of the equity return to follow a normal process with mean 2.1443 and variance 0.8258 . 